INL/EXT-20-57180

Revision 0

\title{
Scoping Studies to Ascertain the Change in the Phase Transition Temperature of Metallic Fuels
}

\section{January 2020}

Miaomiao Jin, Robert Schley, Larry Aagesen, and David Hurley Idaho National Laboratory

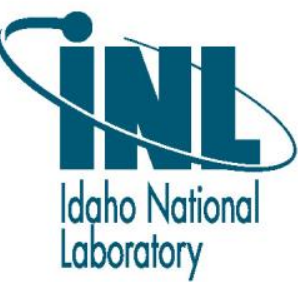




\section{DISCLAIMER}

This information was prepared as an account of work sponsored by an agency of the U.S. Government. Neither the U.S. Government nor any agency thereof, nor any of their employees, makes any warranty, expressed or implied, or assumes any legal liability or responsibility for the accuracy, completeness, or usefulness, of any information, apparatus, product, or process disclosed, or represents that its use would not infringe privately owned rights. References herein to any specific commercial product, process, or service by trade name, trade mark, manufacturer, or otherwise, does not necessarily constitute or imply its endorsement, recommendation, or favoring by the U.S. Government or any agency thereof. The views and opinions of authors expressed herein do not necessarily state or reflect those of the U.S. Government or any agency thereof. 
INL/EXT-20-57180

Revision 0

\section{Scoping Studies to Ascertain the Change in the Phase Transition Temperature of Metallic Fuels}

Miaomiao Jin, Robert Schley, Larry Aagesen and David Hurley

January 2020

Idaho National Laboratory

Idaho Falls, Idaho 83415

http://www.inl.gov

Prepared for the

U.S. Department of Energy

Office of Nuclear Energy

Under DOE Idaho Operations Office

Contract DE-AC07-05ID14517 
Page intentionally left blank 


\section{EXECUTIVE SUMMARY}

Microstructure evolution due to irradiation in a nuclear reactor can have a dramatic effect on material properties. A better understanding of this evolution is necessary for developing improved nuclear fuels and materials. In the current scoping study we evaluate the influence of irradiation induced defects on the recrystallization temperature of a single component fuel surrogate. 
Page intentionally left blank 


\section{CONTENTS}

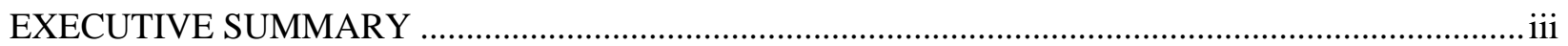

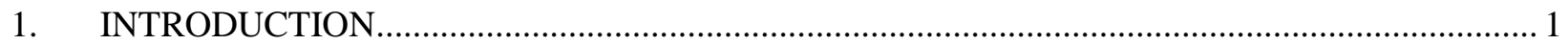

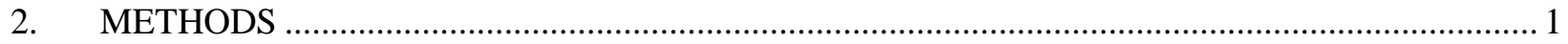

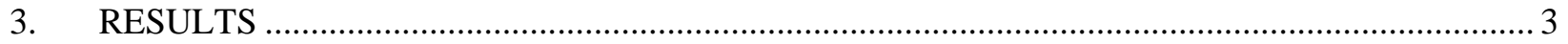

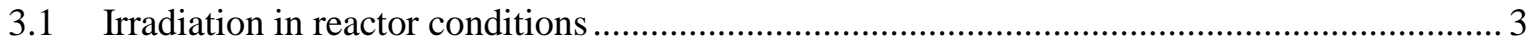

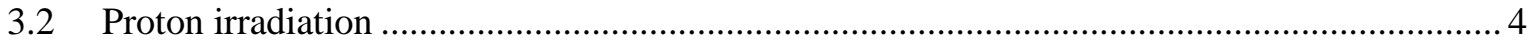

References

\section{FIGURES}

Figure 1. Predicted shift in the recrystallization temperature of a copper alloy due to radiation

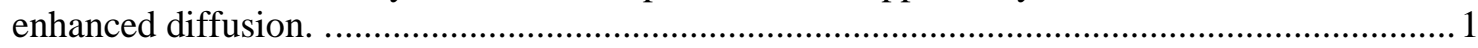

Figure 2. Radiation enhanced diffusion dose rates corresponding to different reactor conditions.............. 4

Figure 3. Radiation SRIM/TRIM estimation of defect production...........................................................5

Figure 4. Radiation enhanced diffusion including proton irradiation ....................................................... 5

\section{TABLES}

Table 1. Parameters used in the point defect kinetics model. 3 
Page intentionally left blank 


\section{Scoping Studies to Ascertain the Change in the Phase Transition Temperature of Metallic Fuels}

\section{INTRODUCTION}

Microstructural transformations of nuclear fuel can be dramatically influenced by irradiation. Key examples include radiation induced grain subdivision in silicide fuel [1] and radiation induced spinodallike decomposition in metallic fuel [2]. In the current scoping study we evaluate the influence of irradiation induced defects on the recrystallization temperature of a single component fuel surrogate. Recrystallization occurs in both oxide and metallic fuel and can cause dramatic changes in material properties $[3,4,5]$.

The surrogate sample considered in the current modeling-based study was taken to have microstructure dominated by dislocations, representative of that found in metallic fuel under irradiation. Typically, under irradiation dislocations multiply due a dislocation sink bias for interstitials. The strain energy associated with dislocation production coupled with high temperatures cause the material to recrystallize, much in the same way highly deformed metals recrystallize. However, uniformly introducing dislocations in bulk samples is not possible using ion beams and is extraordinarily costly and time consuming using a test reactor. As an alternative we considered a case where dislocations are introduced by deformation. Specifically we consider a microstructure representative of that found in a body center cubic metal subjected rolling deformation. It is important to note that a rolling microstructure pairs nicely with previous and planned experiments using a resonant ultrasound spectroscopic instrument (RUSL) currently under development within the I2 program.

\section{METHODS}

There have been several studies that demonstrate that radiation damage brings about an acceleration in the recrystallization process [6-8]. Essentially radiation damage creates a large number of vacancies and interstitials. These point defects lead to an enhancement of the mass diffusion coefficient. Because recrystallization is a diffusion controlled process, radiation enhanced diffusion results in a lowering of the recrystallization temperature. Following the work of Zinkle et al. [8], a predication of the shift in temperature can be made by assuming that accelerated recrystallization is solely driven by radiation enhanced diffusion. This approach involves calculating the thermal diffusion coefficient required to bring about recrystallization. For example, Fig. 1 shows the predicted diffusion coefficient for a copper alloy. Without irradiation, this alloy recrystallizes at $480^{\circ} \mathrm{C}$. The thermal diffusion coefficient at this temperature is $3 \times 10^{-19}$ $\mathrm{m}^{2} / \mathrm{s}$. During ion irradiation at $2 \times 10^{-3} \mathrm{dpa} / \mathrm{s}$, the radiation diffusion coefficient equals $3 \times 10^{-19} \mathrm{~m}^{2} / \mathrm{s}$

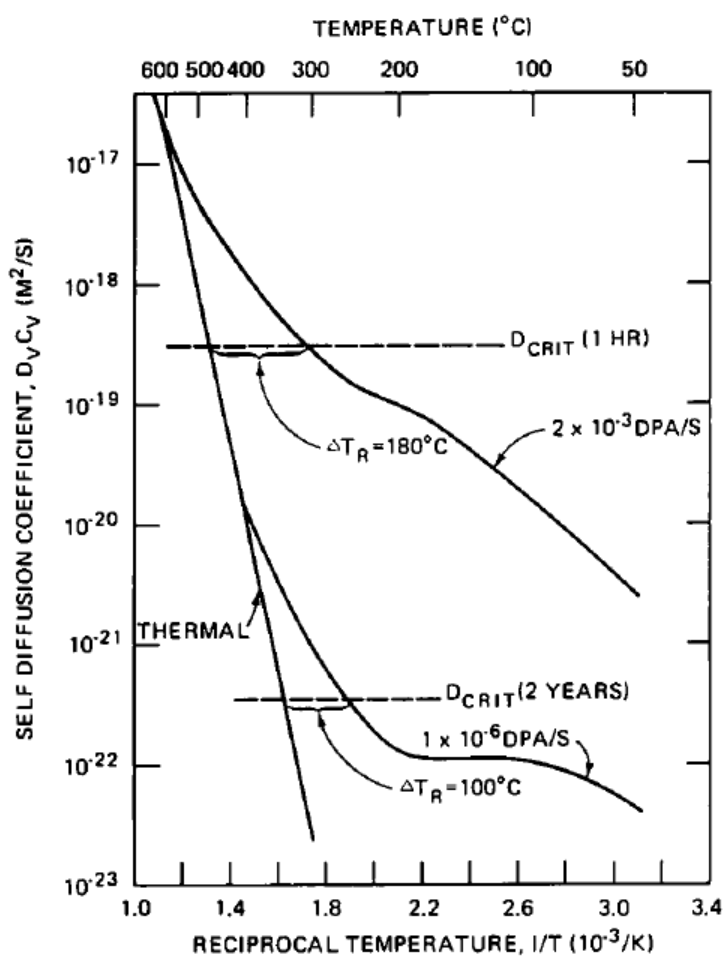

Figure 1. Predicted shift in the recrystallization temperature of a copper alloy due to radiation enhanced diffusion. From Zinkle et al. [8]. at a temperature $\sim 300^{\circ} \mathrm{C}$. The shift in irradiation temperature is $\sim 180^{\circ} \mathrm{C}$. 
To calculate the influence of irradiation on recrystallization temperature we use a simple model of radiation-enhanced diffusivity. The system is simplified with point defect kinetics [3], which described the time variation of vacancy $\left(C_{v}\right)$ and interstitial $\left(C_{i}\right)$ concentrations based on production, recombination, and losses at sinks.

$$
\begin{aligned}
& \frac{\mathrm{d} C_{v}}{\mathrm{~d} t}=K_{0}-K_{i v} C_{i} C_{v}-K_{v s} C_{v} C_{s} \\
& \frac{\mathrm{d} C_{v}}{\mathrm{~d} t}=K_{0}-K_{i v} C_{i} C_{v}-K_{i s} C_{i} C_{s}
\end{aligned}
$$

where $K_{0}$ is the defect production rate, $K_{i v}$ is the vacancy-interstitial recombination rate coefficient, $K_{v s}$ is the vacancy-sink reaction rate coefficient, and $K_{i s}$ is the interstitial-sink reaction rate coefficient. At steady state when the time derivation becomes zero, the concentrations are written as:

$$
\begin{aligned}
& C_{v}^{s s}=-\frac{K_{i s} C_{s}}{2 K_{i v}}+\left[\frac{K_{0} K_{i s}}{K_{i v} K_{v s}}+\frac{K_{i s}^{2} C_{s}^{2}}{4 K_{i v}^{2}}\right]^{1 / 2} \\
& C_{i}^{s s}=-\frac{K_{v s} C_{s}}{2 K_{i v}}+\left[\frac{K_{0} K_{v s}}{K_{i v} K_{i s}}+\frac{K_{v s}^{2} C_{s}^{2}}{4 K_{i v}^{2}}\right]^{1 / 2}
\end{aligned}
$$

Because interstitial diffusivity is normally much larger than that of vacancy, $K_{i v}$ can be written as:

$$
K_{i v}=\frac{z_{i v} \Omega D_{i}}{a^{2}}
$$

Considering that dislocations are the only sinks within a grain and defect-dislocation reaction is diffusion controlled, the following expressions are used to solve Eqs. 3-4.

$$
\begin{gathered}
K_{v s}=\frac{2 \pi D_{v}}{\ln \left(R / R_{v d}\right)} \\
K_{i s}=\frac{2 \pi D_{i}}{\ln \left(R / R_{i d}\right)} \\
\text { Where, } \quad R=1 / \sqrt{\pi \rho}, D=D_{0} \exp \left(\frac{-E_{m}}{k_{b} T}\right)
\end{gathered}
$$

All other parameter definitions and values are provided in Table 1 . The dislocation density for the finetextured pure copper sample was not measured, hence the dislocation density is estimated to be $1.0 \times 10^{15}$ $/ \mathrm{m}^{2}$ [4]. Then, assuming correlation jumps are neglected, the radiation-enhanced diffusion coefficient can be obtained as:

$$
D_{\mathrm{rad}}=D_{v} C_{v}+D_{i} C_{i}
$$


Table 1. Parameters used in the point defect kinetics model.

\begin{tabular}{|l|l|l|}
\hline Parameter & Value & Reference \\
\hline Vacancy migration barrier $E_{m}^{v}$ & $0.71 \mathrm{eV}$ & {$[5]$} \\
\hline Interstitial migration barrier $E_{m}^{i}$ & $0.12 \mathrm{eV}$ & {$[5]$} \\
\hline Vacancy formation energy $E_{f}^{v}$ & $1.3 \mathrm{eV}$ & {$[5]$} \\
\hline Lattice parameter $a$ & $3.61^{\circ} \mathrm{A}$ & \\
\hline Atomic volume $\Omega$ & $11.7615^{\circ} \mathrm{A}^{3}$ & \\
\hline Dislocation density $\rho$ & $1.0 \times 10^{15} / \mathrm{m}^{2}$ & See text \\
\hline Vacancy-interstitial interaction factor $z_{i v}$ & 500 & {$[3]$} \\
\hline Vacancy-dislocation capture radius $R_{v d}$ & 500 & {$[3]$} \\
\hline Interstitial-dislocation capture radius $R_{i d}$ & 500 & {$[3]$} \\
\hline Defect survival fraction from primary damage & 0.15 & Assumption \\
\hline Interstitial diffusion pre-factor $D_{0}^{i}$ & $2 \times 10^{-3} \mathrm{~cm}^{2} / s$ & {$[9]$} \\
\hline Vacancy diffusion pre-factor $D_{0}^{v}$ & $0.25 \mathrm{~cm}^{2} / s$ & {$[9]$} \\
\hline Temperature $T$ & Varying & \\
\hline
\end{tabular}

\section{RESULTS}

\subsection{Irradiation in reactor conditions}

Given the parameters in Table $1, D_{\text {rad }}$ is calculated considering various dose rates (i.e. different radiation conditions) including

- TREAT reactor at $100 \mathrm{~kW}: 1.83 \times 10^{-10} \mathrm{dpa} / \mathrm{s}$

- TREAT reactor at $2 \mathrm{MW}: 3.66 \times 10^{-9} \mathrm{dpa} / \mathrm{s}$

- NRAD reactor at $0.25 \mathrm{MW}: 6.7 \times 10^{-10} \mathrm{dpa} / \mathrm{s}$

Figure 2 depicts the results. At $500^{\circ} \mathrm{K}$ there is very little difference between the thermal diffusion coefficient and the radiation enhanced coefficient. Note that the thermal diffusivity in the plot only considers bulk diffusion, and does not include fast diffusion pathways such as grain boundaries. The transition temperature where $D_{\text {rad }}$ begins to dominate $D_{\text {thermal }}$ varies with dose rates, marked in Figure 2 . This temperature range is between $460^{\circ} \mathrm{K}$ to $500^{\circ} \mathrm{K}$. Below these temperatures, radiation can enhance diffusion, and as a consequence accelerate the recrystallization process. However, in the experiment, it turns out that these radiation conditions exhibited negligible effect on the recrystallization process around the test recrystallization temperature of $150^{\circ} \mathrm{C}\left(423^{\circ} \mathrm{K}\right)$ [10]. Such a contradiction may highlight the importance of other diffusion routes, such as grain boundaries that are abundant in the heavily textured sample. For comparison we have plotted the expected grain boundary diffusivity for textured Fe, the slope of which is the migration energy (dashed line in Fig. 2). At low temperatures, grain boundary 


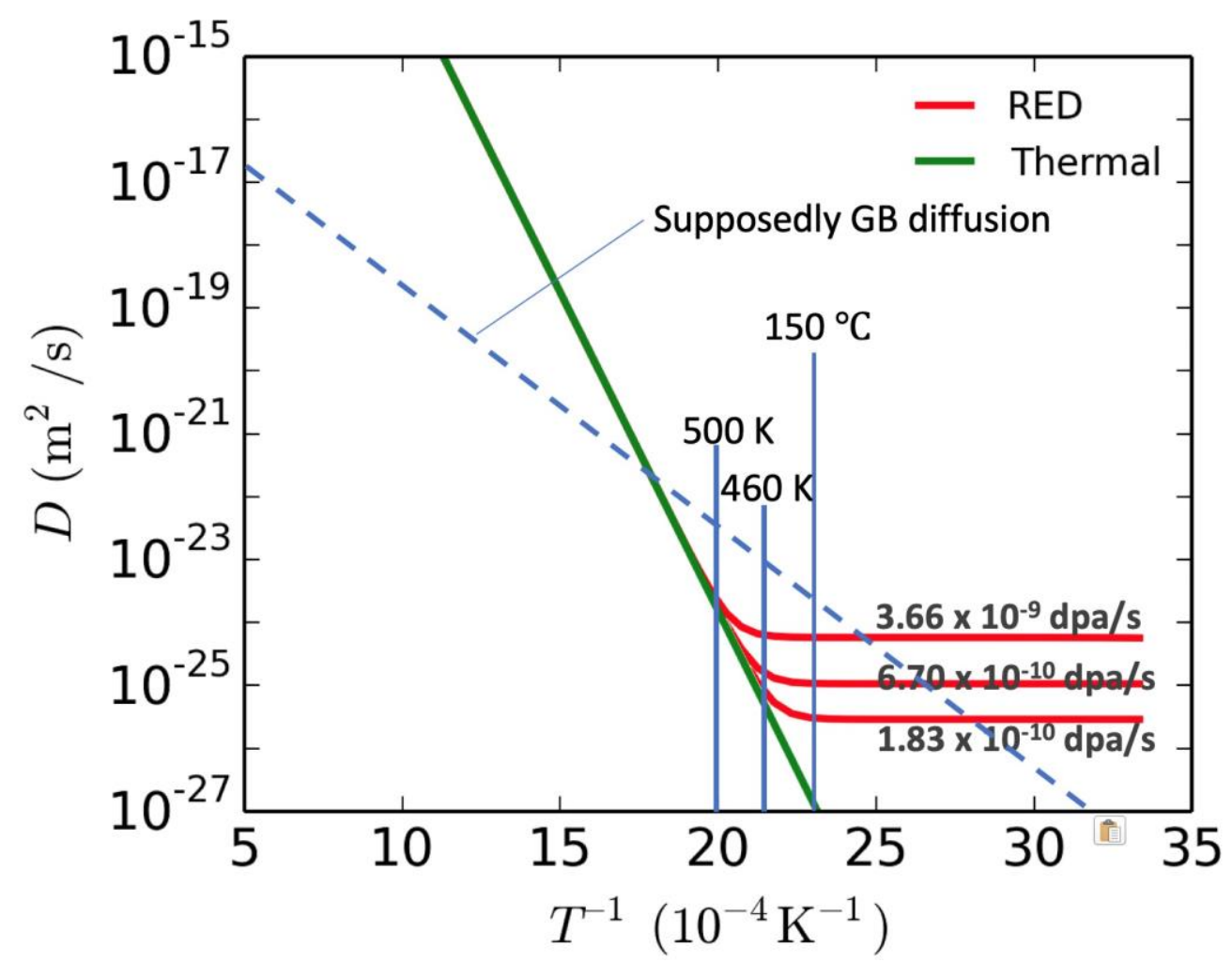

Figure 2. Radiation enhanced diffusion at various dose rates, corresponding to different reactor conditions. Thermal diffusion is included as green line for comparison. RED stands for radiation-enhanced diffusion. The dashed line marks the presumable grain boundary mechanism. The temperature range from $460^{\circ} \mathrm{K}$ to $500^{\circ} \mathrm{K}$ is marked where diffusion transitions to being radiation enhanced. $150^{\circ} \mathrm{C}$ marks the experiment temperature where recrystallization occurs.

diffusion is the dominant diffusion mode, while at high temperature, bulk diffusion becomes dominant because of a much larger volume fraction. If grain boundary diffusion were considered, the intersection between $D_{\text {rad }}$ and $D_{\text {thermal }}$ would occur at a lower value of $T$ (i.e. higher $1 / T$ ). This implies, with or without these low dose rate radiation conditions, the diffusion behavior is similar due to grain boundary diffusion. Hence, to observe a clear contrast between irradiated and unirradiated cases, it is recommended to lower the temperature or increase the dose rate. However, lowering the temperature may bring ensuing consequences such as amorphization. Therefore, increasing the dose rate using ion irradiation could be a viable approach.

\subsection{Proton irradiation}

Proton irradiation is proposed to examine the recrystallization process due to its high dose rate and longrange penetration. We use ion conditions typical of the 3 MV Pelletron Accelerator located at Sandia National Laboratory. We chose this ion beam facility because of the potential of utilizing a transient grating spectroscopy instrument to monitor changes in elastic properties during ion irradiation. The capacity of the accelerator at Sandia National Laboratory is given below:

- Proton Energy: single eVs to 4.5 MeV.

- Beam flux $f: 5 \times 10^{11}$ ions $/\left(\mathrm{cm}^{2} s\right)$ to $1 \times 10^{13}$ ions $/\left(\mathrm{cm}^{2} s\right)$. 

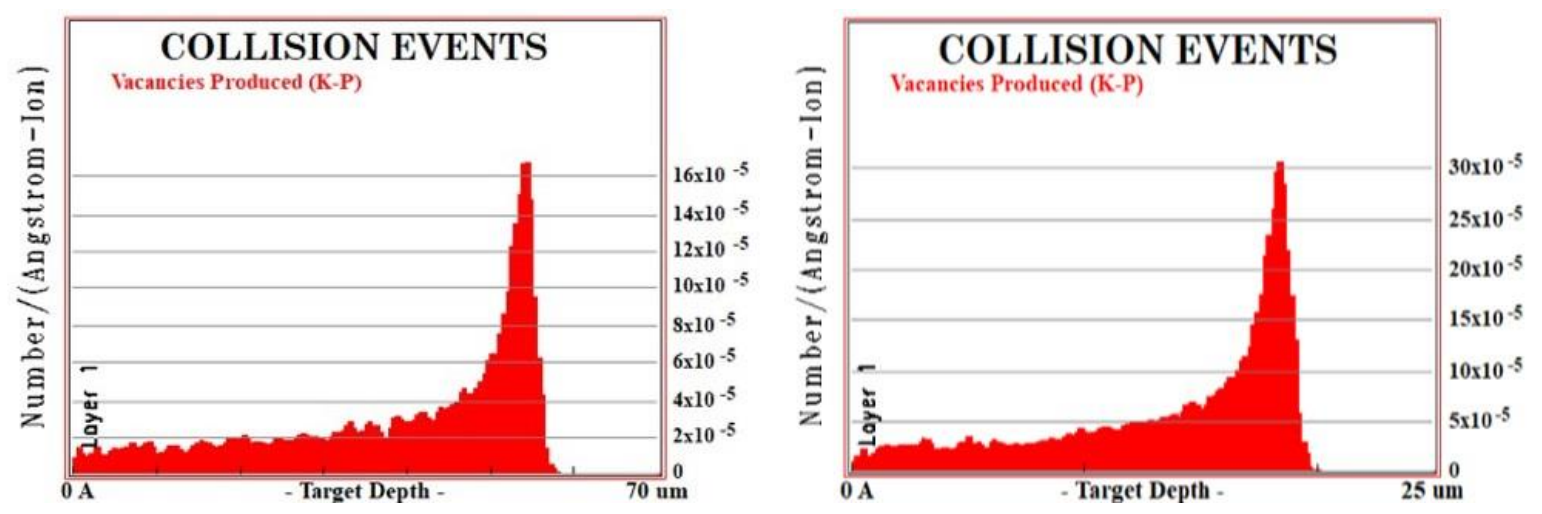

Figure 3. Radiation SRIM/TRIM estimation of defect production. Left: using $4 \mathrm{MeV}$ proton to $\mathrm{Cu}$ layer, Right: using $2 \mathrm{MeV}$ proton to $\mathrm{Cu}$ layer.

The dose rate and proton range can be estimated with the SRIM/TRIM package [11] with recommended settings based on [12]. These settings include $\mathrm{Cu}$ as base material, incident $\mathrm{H}^{+}$ions, lattice binding energy $0 \mathrm{eV}$, displacement threshold energy $30 \mathrm{eV}$ [13], quick mode, and 99999 ions for statistics. Figure 3 demonstrates the defect production along the depth. It can be seen for $4 \mathrm{MeV}$ protons, the penetration depth (60 microns) is much larger than that of $2 \mathrm{MeV}$ protons (20 microns). Considering a bulk polycrystalline sample, a larger depth is preferred to eliminate surface effects. Hence, $4 \mathrm{MeV}$ is likely to

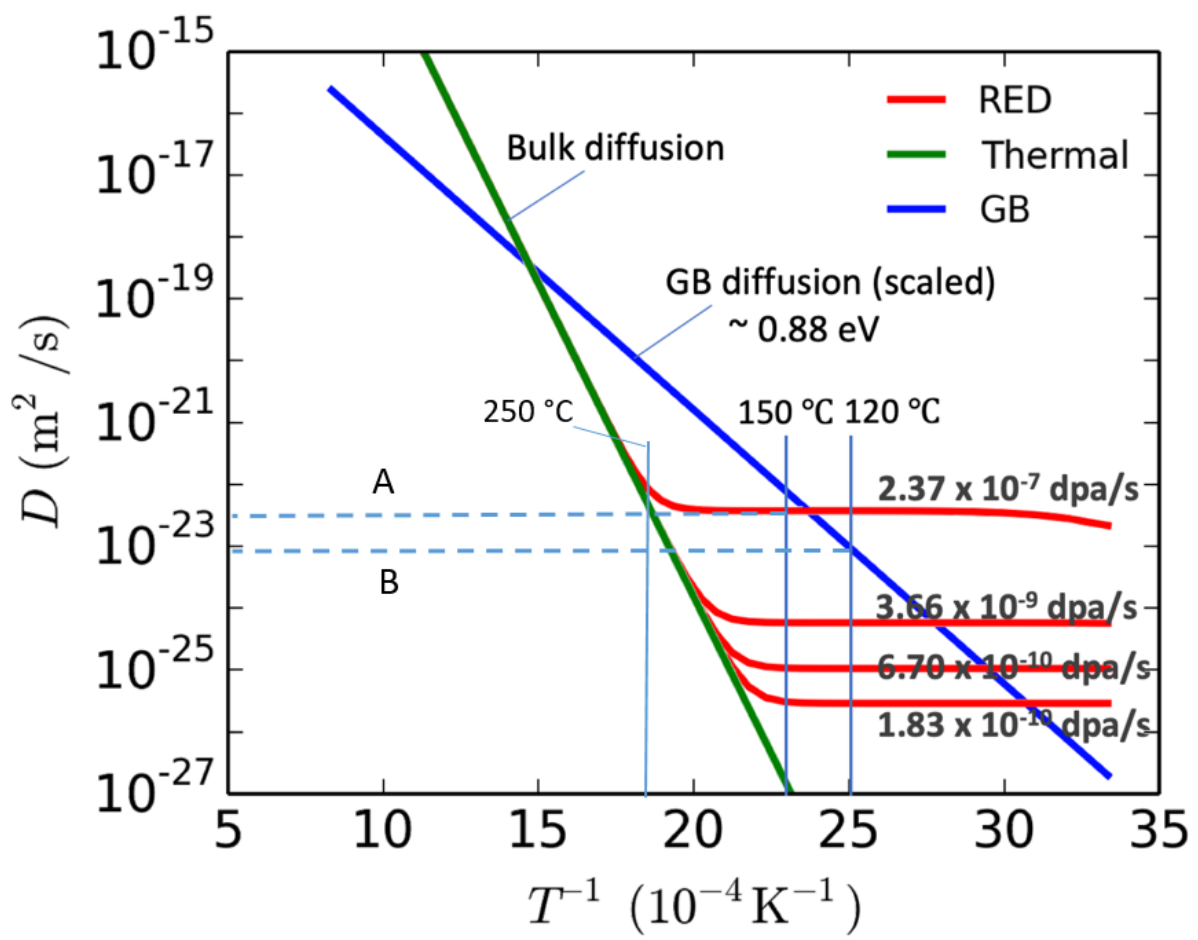

Figure 4. Radiation enhanced diffusion at various dose rates including proton irradiation $\left(2.37 \times 10^{-7} \mathrm{dpa} / \mathrm{s}\right)$. The blue line marks the presumable fast diffusion path through grain boundaries with a lower activation barrier than that of bulk diffusion. $150^{\circ} \mathrm{C}$ marks the temperature where previous recrystallization experiments were conducted. 
be used for irradiation. The defect production rate across the plateau region is around $2 \times 10^{-5} /\left({ }^{\circ} \mathrm{A} \cdot\right.$ ion). Therefore, the dose rate can be estimated to be $2.37 \times \mathbf{1 0}^{-7} \mathrm{dpa} / \mathrm{s}$, assuming beam flux $1 \times 13$ ions $/\left(\mathrm{cm}^{2} s\right)$. $D_{\text {rad }}$ for proton irradiation has been plotted in Figure 4 on top of the neutron radiation conditions (Figure 2). The saturation of the radiation enhanced diffusivity with decreasing temperature (increasing $1 / \mathrm{T}$ ) is due to the fact that vacancies are always being created regardless of the irradiation temperature. However, because we have neglected grain boundary diffusion, the correct relationship in this region most likely is not captured. If only bulk diffusion is considered, we would expect to see a radiation induced change in the recrystallization below about $250^{\circ} \mathrm{C}$ (see horizontal dashed line labeled A). For comparison, an estimate of the grain boundary diffusion in polycrystal $\mathrm{Cu}$ is plotted as a blue line in the figure. The estimate is based on the Arrhenius relation with an activation energy around $0.88 \mathrm{eV} \mathrm{[14]} \mathrm{and} \mathrm{assumes} \mathrm{a}$ 10 micron grain size versus a 5 angstrom grain boundary width. Based on this estimate, grain boundary diffusion is dominant for temperatures in the range of about $400^{\circ} \mathrm{C}$ down to about $140^{\circ} \mathrm{C}$ where the grain boundary diffusion curve and the radiation enhanced diffusion curve intersect. We would expect to see radiation effects at temperatures below this. At $120^{\circ} \mathrm{C}$, for example, the diffusion would increase from about $1 \times 10^{-23} \mathrm{~m}^{2} / \mathrm{s}$ (dashed line labelled B) to $5 \times 10^{-22} \mathrm{~m}^{2} / \mathrm{s}$ under proton irradiation. We can conclude that for radiation effects to be noticeable, an appropriate temperature for a given experiment would require an accurate estimation of the diffusion including grain boundary effects (based on the final textured sample). A temperature below the intersection of the normal and radiation enhanced diffusion could then be selected. The duration of the transformation should also be considered. Based on this simple analysis, it appears that the dose rate provided by proton irradiation is sufficient to see an influence on recrystallization of polycrystal $\mathrm{Cu}$.

\section{References}

[1] M.G. Marquez, A.M. Ougouag, and B. Petrovic, Model for radiation damage-induced grain subdivision and its influence in U3Si2 fuel swelling, Annals of Nuclear Energy (2017), doi.org//10.1016/j.anucene.2017.08.045.

[2] Tiankai Yao, Adrian Wagner, Xiang Liu, Anter EI-Azab, Jason Harp, Jian Gan, David H Hurley, Michael T Benson, Lingfeng He, On Spinodal-like Phase Decomposi-tion in U-50 Zr Alloy, Materialia(2020), doi.org/10.1016/j.mtla.2020.100592

[3] Talita Gama de Sousa, Vitor Luiz Sordi, and Luiz Paulo Brand ao. Dislocation density and texture in copper deformed by cold rolling and ecap. Materials Research, 21(1), 2018.

[4] S.M. Foiles, M.I. Baskes, and M.S. Daw. Embedded-atom-method functions for the fcc metals cu, ag, au, ni, pd, pt, and their alloys. Physical review B, 33(12):7983, 1986.

[5] S. J. Zinkle, R. A. Dodd, and G. L. Kulcinski, in: Effects of Radiation on Materials; $12^{\text {th }}$ Intern. Symp., ASTM STP 870, Eds. F. A. Garner and J.S. Perrin (American Society for Testing and Materials, Philadelphia, 1985) P. 363.

[6] S. J. Zinkle, R. A. Dodd, and G.L. Kulcinski, J. Nucl. Materials, 133\&134 (1985) 680.

[7] S. J. ZInkle, G. L. Kulcinski, and L. K. Mansur, J. Nucl. Materials, 141-143 (1986) 188.

[8] M.J. Caturla, N. Soneda, E. Alonso, B.D. Wirth, T. Diaz de la Rubia, and J.M. Perlado. Comparative study of radiation damage accumulation in cu and fe. Journal of nuclear materials, 276(1-3):13-21, 2000 . 
[9] R.S. Schley, L.K. Aagesen, Z. Hua, D.H. Hurley, Detailed Analysis of RUS Insertion Experiment and Scoping Studies for Performing Next Experiment using an Enriched Fuel Sample, Idaho National Laboratory, INL/EXT-19-55962.

[10] J.F. Ziegler and J.P. Biersack. The stopping and range of ions in matter. In Treatise on heavy-ion science, pages 93-129. Springer, 1985.

[11] Roger E Stoller, Mychailo B Toloczko, Gary S Was, Alicia G Certain, Shyam Dwaraknath, and Frank A Garner. On the use of srim for computing radiation damage exposure. Nuclear instruments and methods in physics research section B: beam interactions with materials and atoms, 310:7580, 2013.

[12] Kai Nordlund, Andrea E Sand, Fredric Granberg, Steven J Zinkle, Roger Stoller, Robert S Averback, Tomoaki Suzudo, Lorenzo Malerba, Florian Banhart, William J Weber, et al. Primary radiation damage in materials. Report prepared by the OECD/NEA Working Party on Multiscale Modelling of Fuels and Structural Materials for Nuclear Systems, Expert Group on Primary Radiation Damage Nuclear Science NEA/NSC/DOC, 9, 2015.

[13] Surholt, T., and Chr Herzig. "Grain boundary self-diffusion in Cu polycrystals of different purity." Acta materialia 45.9 (1997): 3817-3823. 